\title{
Is sexual risk taking behaviour changing in rural south-west Uganda? Behaviour trends in a rural population cohort 1993-2006
}

\author{
S Biraro, ${ }^{1}$ L A Shafer, ${ }^{1}$ I Kleinschmidt, ${ }^{2}$ B Wolff, ${ }^{1}$ A Karabalinde, ${ }^{1}$ A Nalwoga, \\ J Musinguzi, ${ }^{3}$ W Kirungi, ${ }^{3}$ A Opio, ${ }^{3}$ J Whitworth, ${ }^{4}$ H Grosskurth ${ }^{1}$
}

\begin{abstract}
${ }^{1}$ Medical Research Council (MRC)/Uganda Virus Research Institute (UVRI) Uganda Research Unit on AIDS, Entebbe, Uganda; ${ }^{2}$ London School of Hygiene and Tropical Medicine, London, UK; ${ }^{3}$ Ministry of Health, Government of Uganda;

${ }^{4}$ Wellcome Trust

Correspondence to: Dr L A Shafer, MRC/UVRI Uganda Research Unit on AIDS, P 0 Box 49, Entebbe, Uganda: leighanne.shafer@mrcuganda. org
\end{abstract}

Accepted 19 January 2009

\section{ABSTRACT}

Objective: To describe sexual behaviour trends in a rural Ugandan cohort in the context of an evolving HIV epidemic, 1993-2006.

Methods: Sexual behaviour data were collected annually from a population cohort in which HIV serological surveys were also conducted. Behaviour trends were determined using survival analysis and logistic regression. Trends are reported based on the years in which the respective indicators were collected.

Results: Between 1993 and 2006, median age at first sex increased from 16.7 years to 18.2 years among $17-$ 20-year-old girls and from 18.5 years to 19.9 years among boys. Both sexes reported a dip in age at sexual debut between 1998 and 2001. One or more casual partners in the past 12 months among men rose from $11.6 \%$ in 1997 to $12.7 \%$ in 2004 and then declined to $10.2 \%$ in 2006 . Among women it increased from $1.4 \%$ in 1997 to $3.7 \%$ in 2004 and then reduced to $1.4 \%$ in 2006 . The rise in casual partners between 1997 and 2004 was driven mainly by older age groups. Trends in condom use with casual partners varied by age, increasing among those aged 35+ years, declining in the middle age groups and presenting a dip and then a rise in the youngest aged group (13-19 years).

Conclusion: Among youth, risky behaviour declined but increased in the late 1990s/early 2000s. Among those aged $35+$ years, condom use rose but casual partners also rose. Several indicators portrayed a temporary increase in risk taking behaviour from 1998 to 2002.

In the context of the HIV/AIDS epidemic, the carefully conducted documentation of population trends in self-reported sexual behaviour is required for a number of reasons. Perhaps the most important is that data on behavioural changes can alert policymakers and intervention programme managers of developments that necessitate the adaptation of ongoing intervention strategies. Second, trends in reported behaviour can help to interpret observed epidemiological changes in HIV infection and other sexually transmitted infections. Through comparative analyses, they also help to better understand differences in the course of the HIV epidemic between countries; they may be useful in feeding mathematical models designed to predict the course of the epidemic and the most cost-effective intervention measures. Lastly, behavioural data are also of interest to anthropological research in their own right.
In Uganda, data on sexual behaviour and their trends over time are available from national surveys, demographic and health surveys, sentinel surveillance groups and from a few longitudinal cohort studies accompanied by qualitative surveys. ${ }^{1-5}$ National cross-sectional surveys and data from sentinel groups such as antenatal clinic attenders should be supplemented by longitudinal data gathered from annual surveys of well characterised cohorts. Such data refer to a smaller geographical area, but any trends observed are related to an identical study population and can offer more detailed insights, particularly if combined with qualitative behavioural research conducted in the same community.

Several studies have documented changes in sexual behaviour in Uganda leading to a decrease in risk taking during the 1990s, and various researchers have used these observations to explain the declines observed in the HIV epidemic during that period. ${ }^{2}{ }^{6-9}$ We have previously documented sexual behaviour as well as HIV prevalence and incidence in a rural population cohort from southwest Uganda that has been studied since 1989.3 1011 Here we provide an update on trends in selfreported sexual behaviour in this cohort, covering the period from 1997 to 2006.

According to guidelines from the World Health Organization (WHO) and the Joint United Nations Programme on HIV/AIDS (UNAIDS) for the second-generation surveillance of the HIV epidemic including sexual behaviour, three indicators have been suggested as essential for behavioural surveillance:12 age at sexual debut, number of sexual partners and condom use. In this paper we combine information on these indicators with additional important parameters such as secondary abstinence, pregnancy among unmarried participants, as well as the lag time between sexual debut and first marriage.

\section{METHODS}

\section{Study setting}

The general population cohort studied by the MRC Unit in Uganda has been described before. ${ }^{3} 1314$ Briefly, this open cohort is located in a rural subcounty in the south-west of the country. Since 1989 the MRC has carried out annual populationbased surveys in this cohort. In a private setting, survey teams administer questionnaires to those aged $\geqslant 13$ years on sexual behaviour and other factors and collect a blood sample for HIV testing. The study area, which initially comprised 15 
villages, was expanded in 1999/2000 to 25 villages and now has a population of about 18000 residents. The inclusion criterion for analysis in this study was age $\geqslant 13$ years. Voluntary counselling and testing has been available from the project counsellors since inception of the study in 1989/90. However, uptake has been low ( $<10 \%$ in the first 10 rounds). ${ }^{15}$ Among individuals aged $15-59$ years, approximately $30 \%$ and $35 \%$ had ever received HIV test results by rounds 15 and 16 (survey years 2003 and 2004), respectively. At the baseline survey, polygamy among men was $7.7 \%$ and non-existent among women.

\section{Collection of sexual behaviour data}

To reduce the burden of annual interviews on study participants, not all questions on sexual behaviour were collected at every survey round. Whether or not the respondent had ever had sex was first recorded in 1993, but age at first sex was first asked in 1997 and was then asked annually. Condom use at last sex with any partner was recorded in 1993, 1996, 1997, 1999, 2000, 2001, 2003, 2005 and 2006. Condom use at last sex with a casual partner was recorded every second year from 1997 to 2005. Casual partners were self-defined but, for those respondents who were not sure, interviewers described casual partners as those with whom the respondent had had sex once or a few times only. Information on pregnancies was obtained in most years from 1996 to 2005.

\section{Data management and analysis}

Data were double entered and analysis was performed using Stata Version 9 (Statcorp, Texas, USA).

Two variables were used to describe sexual initiation: median age at first sex and primary abstinence, defined as the percentage of 13-19-year-olds who reported that they were not yet sexually active.

The median age at first sex was determined using survival analysis, censoring those who had not yet had sex. Persons aged 17-20 years were compared across annual survey rounds. This age range was used because it includes the median; it was intentionally narrow in order to assess trends over time with minimal overlap (the same person's sexual debut reported in consecutive years). Trends in median age at first sex were tested using Cox survival analysis.

Secondary abstinence was defined as the percentage of persons aged 13-19 years who reported being sexually active at least once, but to have not been sexually active in the past year. For both primary and secondary abstinence, logistic regression models with a Huber correction to account for multiple observations per individual were employed to examine time trends by age and gender. Time was modelled as a linear variable with a quadratic term to allow detection of non-linear trends over time.

Regarding sexual partners, the percentage of participants reporting at least one casual partner in the past year was determined and analysed by sex, age, marital status and survey year. Logistic regression models were employed separately for men and women. In each model, age, survey year and marital status were included. Adjusted odds ratios (ORs) were calculated by adjusting for all factors in each model other than the one under consideration.

Reporting by the same individual over time in this cohort was similar but not always consistent. As an example, $53 \%$ of those who reported age at first sex in two consecutive years reported exactly the same age (or consistently reported that they had never had sex) in the 2 years. The remaining $47 \%$ of responses usually differed by 1 year and the difference went in both directions (sometimes the respondent reported an older age at sexual debut in the subsequent year and sometimes the reverse). Others have described patterns and trends in consistency of reporting, ${ }^{16}$ but this analysis was not within the scope of this paper. Most of the analyses in this paper treat the responses across time as though they are from a series of cross-sectional surveys; no attempt was made to validate responses by comparing those from the same individual in different survey rounds.

\section{RESULTS}

\section{Sexual behaviour survey coverage}

For the period 1993-9, an average of 6441 participants aged $\geqslant 13$ years took part in the census every year. For 2000-6, after 10 additional villages were included in the study area, an average of 11194 adults participated every year. On average, 57\% of these responded to the sexual behaviour questionnaire at each survey and $82 \%$ responded at least once. For survey rounds for which these data were available, lack of response was due to absence (29\%) and refusal to be interviewed (13\%). No systematic time trend was seen in the participation rates.

\section{Sexual debut, primary and secondary abstinence}

Data on sexual debut were available for the period 1997-2006 and on primary and secondary abstinence for the period 19932006. Among participants aged 17-20 years, reported median age at first sex increased by almost a year from 17.8 years to 18.6 years between 1997 and 2006 ( $p$ for trend <0.001, survival analysis). Parallel trends were observed in girls and boys. A slight and non-significant fall in median age was recorded for both sexes between 1998 and 2000. In girls, reported median age at first sex in the years 1997-2006 was 16.7, 17.4, 17.2, 17.2, $17.5,17.4,17.8,17.8,17.9$ and 18.2 years, respectively. For boys the comparative figures were 18.5, 18.0, 17.6, 17.8, 18.1, 18.6, 18.4, 18.8, 18.7 and 19.9 years.

The proportion of 13-19-year-olds who reportedly never had sex increased from $71.7 \%$ in 1993 to $82.6 \%$ in 2006 (fig 1). Although the overall trend was an increase in primary abstinence over time, both girls and boys experienced several years with a fall in the percentage who had never had sex. Among girls this fall occurred between 1999 and 2002 ( $p$ for change in trend $<0.001$ ), while among boys it was between 1998 and 2000 ( $\mathrm{p}$ for change in trend $=0.005$ ).

Among 13-19-year-olds who had ever had sex, there was an increase over time in those reporting no sexual partners in the past year (secondary abstinence) (fig 1). Among boys, secondary abstinence increased from $9.8 \%$ in 1997 to $28.9 \%$ in 2005 and $21.4 \%$ in 2006 ( $p$ for trend, adjusting for age $=0.001$ ). Among girls, the comparable figures were $12.3 \%$ in 1997 and $17.4 \%$ in 2005, with a fall in 2006 to $14.0 \%$ ( $p$ for trend, adjusting for age $=0.010$ ). Although the general trend was an increase in secondary abstinence, the non-linear trend among girls showed a temporary decline between 1997 and 2002 followed by an increase ( $p$ for change in trend $=0.038$ ). The change in trend was of borderline significance for boys ( $p$ for change in trend $=0.078$ ). In all age groups other than the $13-19$ year age group, secondary abstinence was stable throughout the study period. Reported secondary abstinence among girls in the 1319 year age group was about half of that observed for boys in all years except 1997. By contrast, the oldest women (age $\geqslant 45$ years) had secondary abstinence rates in the order of $65 \%$ in all years (data not shown). This was double the rate of 


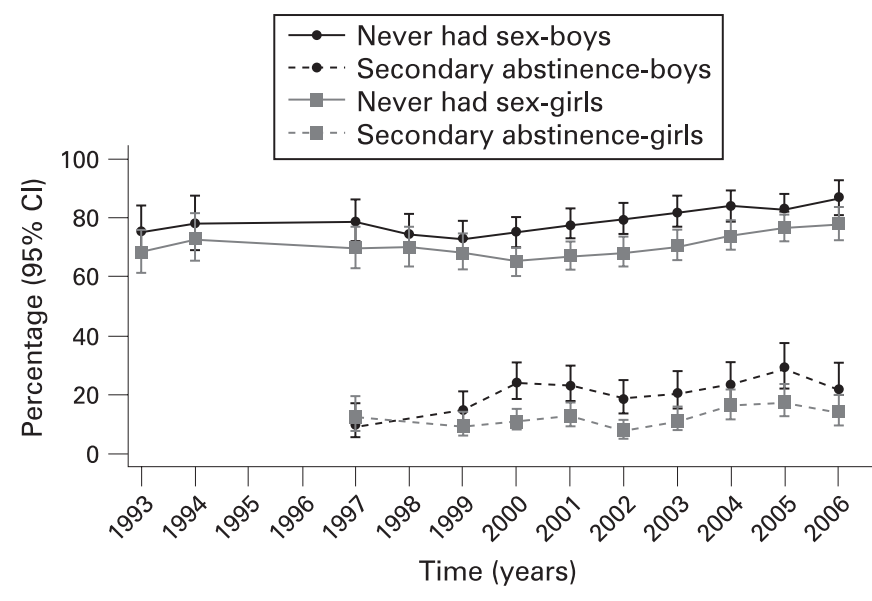

Figure 1 Primary and secondary abstinence in participants aged 13 19 years. Secondary abstinence is defined as no sex in the past year among those who have ever had sex.

secondary abstinence for men in this age group, which was approximately $32 \%$ in all years.

In 1997 the percentage of sexually inactive boys in the 1319 year age group was $81 \%$ and the percentage of sexually inactive girls in this age group was $73 \%$. Among both boys and girls, overall sexual inactivity in the past 12 months fell in 1999 and 2000 before steadily rising until 2006. By 2006 the percentage of sexually inactive boys was $90 \%$ and the percentage of sexually inactive girls was $81 \%$.

The percentage of unmarried young women aged 13-20 years who had ever been pregnant rose from 8\% in 1996 to $10 \%$ in 2003 , before declining again to $8 \%$ in 2004 and $6 \%$ in 2005 (p for trend $=0.010$, $\mathrm{p}$ for change in trend $=0.191$ ). The percentage of unmarried women aged 21-29 years who had ever been pregnant has shown an increasing trend from 53\% in 1996 to $67 \%$ in 2005 ( $p$ for trend $=0.357, p$ for change in trend $=0.252$ ).

\section{Time from sexual debut to first marriage}

The median age at first marriage among women in this cohort rose gradually from 19.0 years to 19.4 years among women aged 13-29 years between 1998 and 2006. Among men in the same age range, median age at first marriage rose from 24.9 years to 25.3 years during the same period. In 2006, $47.6 \%$ of men and $15.5 \%$ of women in the $21-29$ year age group were unmarried.

For men, the median lag time between sexual debut and first marriage fell significantly between 1998 and 2006 from 7.9 years to 6.9 years ( $p$ for trend $=0.001$ ). In contrast, for women the lag time was much shorter and showed no change over time, hovering around 2.2 years for most years between 1998 and 2006 ( $p$ for trend $=0.946$ ).

\section{Casual sexual partners}

Data on casual partners were available for the years 1997-2006. For this analysis, virgins were included in the category of 0 casual partners. The percentage of men reporting one or more casual partners in the past 12 months rose from $11.6 \%$ in 1997 to $12.4 \%$ in 2000 and $12.6 \%$ in 2001 and then declined to $10.7 \%$ in 2005 and $10.2 \%$ in 2006 ( $p$ for change in trend $<0.001$ ). Among women, the percentage reporting $\geqslant 1$ casual partners in the past 12 months was substantially less than among men, but increased from $1.4 \%$ in 1997 to $3.4 \%$ in 2000 and 3.6\% in 2001, after which it reduced to $2.6 \%$ in 2005 and $1.4 \%$ in 2006 (p for change in trend $<0.001$ ). We also evaluated a model in which the year was entered as a categorical variable (table 1). Among both sexes, married people were less likely to report a casual partner in the past year than unmarried participants, although $9.4 \%$ of married men reported a casual partner. Among men, the percentage who reported $\geqslant 1$ casual partners in the past year declined by age group, with the exception of 13-19-year-olds who had fewer casual partners than those aged 20-24 years. Among women the trend was similar (table 1).

The 20-24 year age group had the highest proportion of individuals reporting $\geqslant 1$ casual sexual partners in the past year. Among men, this ranged from $23.4 \%$ in 1997 to $28.3 \%$ in 2001, $25.5 \%$ in 2005 and $24.1 \%$ in 2006 (fig 2). Among women the $13-$ 19 year age group reported casual partners as often as the 20 24 year age group. Significant increases in respondents with $\geqslant 1$ casual partners in the past year were observed between 1997 and 2004 in several age groups, most notably the 25-34 year and 35-44 year age groups. Among 13-19-year-olds the percentage with $\geqslant 1$ casual partners declined from 1997 to 2006, but this was mainly influenced by the fact that primary and secondary abstinence among this age group was increasing (fig 1). Among sexually active individuals, reported casual partners are rising. Other than in the 13-19 year and 20-24 year age groups, the trend of reported casual partners did not differ when the denominator was sexually active individuals; nearly everybody was sexually active. By 2005 the reported number of casual partners had started to decline in all age groups.

The proportion of women reporting $\geqslant 2$ casual partners was $0.2 \%$ in $1997,0.7 \%$ in $2001,0.4 \%$ in 2005 and $0.2 \%$ in 2006 (p for change in trend $=0.034$ ). Among men the percentage reporting $\geqslant 2$ casual partners in the past year was $4.6 \%$ in $1997,6.5 \%$ in $2001,4.7 \%$ in 2005 and $4.5 \%$ in 2006 ( $p$ for change in trend $=0.003$ ). Although the general pattern in the cohort was an increase in those with $\geqslant 2$ casual partners until about 2001/2 and a decline thereafter, men aged 35-44 years experienced a steady incline throughout, from $4.0 \%$ in 1997 to $5.5 \%$ in $2001,6.9 \%$ in 2005 and $6.3 \%$ in 2006 ( $p$ trend $=0.042, p$ change in trend $=0.277$ ).

\section{Partners and current marital status}

Among those not currently married there was a decrease in the proportion of men reporting $\geqslant 1$ partners in the past year from $23.0 \%$ in 1996 to $10.0 \%$ in 2006 ( $p$ trend $<0.001$, p change in trend $=0.142)$ in those aged 13-19 years. Among unmarried men aged $20-24$ years, the proportion reporting $\geqslant 1$ partners in the past year remained fairly stable between 1996 and 2000 (77.0\% in 1996 and $74.8 \%$ in 2000), but thereafter dropped to $54.3 \%$ by 2006 ( $p$ trend $<0.001$, $p$ change in trend $=0.006$ ). Among unmarried women aged 13-19 years there was an overall decline in the percentage reporting $\geqslant 1$ sexual partner in the past year, but it initially increased from $17.2 \%$ in 1996 to $20.2 \%$ in 2000 before decreasing to $12.1 \%$ in 2006 ( $p$ trend $<0.001$, $p$ change in trend $<0.001$ ). The trend was similar among women aged $20-24$ years. It was initially stable between $73.7 \%$ in 1996 and $75.0 \%$ in 2003 before decreasing to $58.0 \%$ in 2006 ( $p$ trend $=0.049, p$ change in trend $=0.076$ ). No significant changes were observed in the other age and sex groups.

Among those currently married there was an increase in the proportion of men aged 25-34 years and 35-44 years reporting $\geqslant 2$ partners in the past year between 1996 and 2002, after which the proportions levelled off. Among men aged 2534 years there was an increase from $27.5 \%$ in 1996 to $37.7 \%$ in 2002 then to $32.0 \%$ in 2006 ( $p$ trend $=0.012$, $p$ change in trend $=0.014$ ). In married men aged 35-44 years the proportion reporting $\geqslant 2$ partners in the past year rose from $15.6 \%$ in 1996 
Table 1 Effects of time, age and marital status on having one or more casual partners in the past 12 months by gender, 1997-2006

\begin{tabular}{|c|c|c|c|}
\hline Explanatory variable & Sample size* & Adjusted odds ratio $(95 \% \mathrm{Cl}) \dagger$ & p Value $\dagger$ \\
\hline \multicolumn{4}{|l|}{ Women } \\
\hline \multicolumn{4}{|l|}{ Age (years) } \\
\hline $13-19$ & $7616(4.0)$ & 1 (reference) & \\
\hline $20-24$ & $3188(3.9)$ & $1.92(1.51$ to 2.45$)$ & $<0.001$ \\
\hline $25-34$ & $4818(2.7)$ & $1.54(1.20$ to 1.97$)$ & 0.001 \\
\hline $35-44$ & $3602(2.5)$ & $1.23(0.95$ to 1.60$)$ & 0.112 \\
\hline $45+$ & $6033(0.8)$ & $0.24(0.18$ to 0.34$)$ & $<0.001$ \\
\hline \multicolumn{4}{|l|}{ Survey year } \\
\hline 1997 & $1677(1.4)$ & 1 (reference) & \\
\hline 1999 & $2222(2.5)$ & 2.01 (1.17 to 3.44$)$ & 0.012 \\
\hline 2000 & $3398(3.4)$ & 2.98 (1.78 to 4.97$)$ & $<0.001$ \\
\hline 2001 & $3599(3.6)$ & $3.01(1.82$ to 5.00$)$ & $<0.001$ \\
\hline 2003 & $3535(2.5)$ & 2.17 (1.29 to 3.64$)$ & 0.004 \\
\hline 2004 & $3805(3.7)$ & 3.25 (1.95 to 5.42$)$ & $<0.001$ \\
\hline 2005 & $3562(2.6)$ & 2.25 (1.33 to 3.81$)$ & 0.002 \\
\hline 2006 & $3464(1.4)$ & $1.27(0.73$ to 2.23$)$ & 0.393 \\
\hline \multicolumn{4}{|l|}{ Marital status } \\
\hline Unmarried & $13505(4.1)$ & 1 (reference) & \\
\hline Married & $11085(1.1)$ & $0.19(0.15$ to 0.24$)$ & $<0.001$ \\
\hline \multicolumn{4}{|l|}{ Men } \\
\hline \multicolumn{4}{|l|}{ Age (years) } \\
\hline $13-19$ & $8055(8.2)$ & 1 (reference) & \\
\hline $20-24$ & $2241(25.8)$ & 4.65 (4.03 to 5.37$)$ & $<0.001$ \\
\hline $25-34$ & $3412(20.4)$ & 4.66 (3.97 to 5.48 ) & $<0.001$ \\
\hline $35-44$ & $2514(13.3)$ & 2.99 (2.45 to 3.64$)$ & $<0.001$ \\
\hline $45+$ & $4943(4.0)$ & $0.74(0.60$ to 0.92$)$ & 0.006 \\
\hline \multicolumn{4}{|l|}{ Survey year } \\
\hline 1997 & $1573(11.6)$ & 1 (reference) & \\
\hline 1999 & $2026(11.1)$ & $1.03(0.81$ to 1.30$)$ & 0.818 \\
\hline 2000 & $2857(12.4)$ & $1.23(0.99$ to 1.52$)$ & 0.065 \\
\hline 2001 & 3139 (12.6) & 1.25 (1.01 to 1.54$)$ & 0.041 \\
\hline 2003 & 2959 (11.6) & $1.19(0.96$ to 1.48$)$ & 0.117 \\
\hline 2004 & 3105 (12.7) & 1.35 (1.10 to 1.68$)$ & 0.005 \\
\hline 2005 & $2774(10.7)$ & $1.13(0.90$ to 1.41$)$ & 0.284 \\
\hline 2006 & 2735 (10.2) & 1.06 (0.85 to 1.33$)$ & 0.585 \\
\hline \multicolumn{4}{|l|}{ Marital status } \\
\hline Unmarried & $12579(12.7)$ & 1 (reference) & \\
\hline Married & $8031(9.4)$ & $0.47(0.41$ to 0.54$)$ & $<0.001$ \\
\hline
\end{tabular}

*Values in parentheses are the percentage with $\geqslant 1$ casual partners.

$\uparrow$ Adjusted odds ratio adjusts for the factors in the models other than the one in consideration (four categorical age variables, seven year variables and one categorical variable for marital status).

Logistic regression Wald test with Huber correction.

Figure 2 Individuals reporting one or more casual partners in the past year by age and gender of respondent. Denominator is all respondents except where indicated; sa, sexually active.

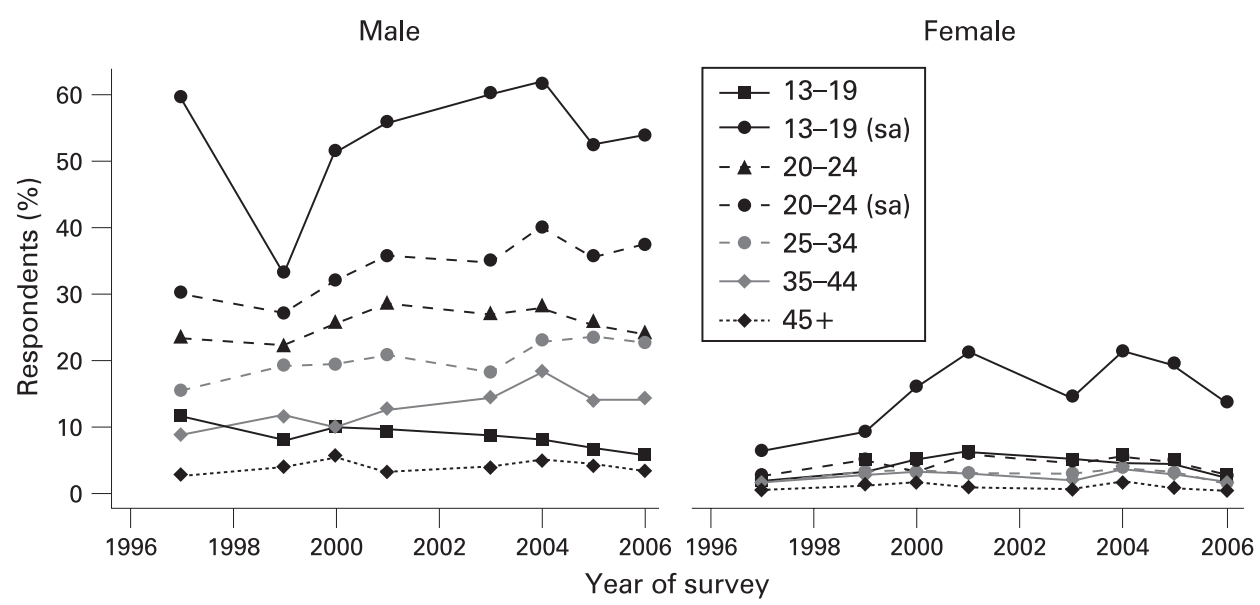




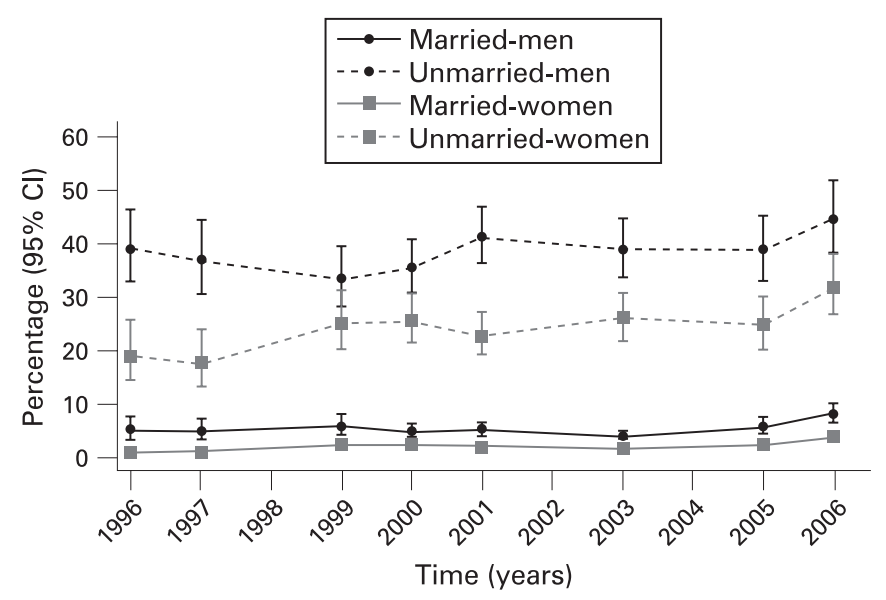

Figure 3 Use of condom at last sex by gender and marital status.

to $36.2 \%$ in 2002 and then levelled off to $34.4 \%$ by 2006 (p trend $=0.001, p$ change in trend $=0.009$ ). There were no significant changes in the other age and sex groups.

\section{Condom use}

Data on condom use ever were available for the survey years 1993-2006, but on condom use at last sex these data were available for 1996-2006. The proportion of respondents who reported having ever used condoms among those who had ever had sex increased steadily from $7.7 \%$ (males $12.5 \%$, females $4.0 \%$ ) in 1993 to $36.7 \%$ (males $46.1 \%$, females 30.7\%) in 2006 . Condom use at last sex, however, shows a rather different trend. Condom use at last sex among men declined from 18.9\% in 1996 to $15.3 \%$ in 2000 and $14.7 \%$ in 2003 , then increased to $15.6 \%$ in 2005 and $18.1 \%$ in 2006 ( $p$ change in trend <0.001). Among women the corresponding figures were 5.7\% in 1996 to $8.6 \%$ in 2000 , followed by a fall to $7.3 \%$ in $2001,8.0 \%$ in 2003 and $7.6 \%$ in 2005 , and finally a rise to $9.9 \%$ in 2006 (p change in trend $=0.605$, not statistically significant). Both sexes reported declining condom use by age. Married people in this population rarely use condoms (fig 3). Unmarried women were 11.4 times more likely to have used a condom at last sex, while unmarried men were 7.0 times more likely than married persons.
Condom use with the last casual partner increased among the two oldest age groups (age 35-44 years and 45+ years. It declined in the middle age groups and showed a changing trend (declining and then rising) in 13-19-year-olds (fig 4). Note that condom use at last sex with a casual partner was not asked in as many survey rounds as condom use at last sex with anybody. Among those aged 35-44 years, condom use with the last casual partner rose from 38.9\% in 1997 (when this question was first asked) to $47.6 \%$ in 2005 (data on this indicator not available for 2006). Among those aged 45+ years it rose from 10.0\% in 1997 to $31.3 \%$ in 2005 . By contrast with the older age groups, the middle age groups experienced a decline in condom use at last sex with a casual partner. The trends in condom use at last sex with a casual partner described here were mainly influenced by men. Condom use with a casual partner among women remained fairly stable over time, in the order of $40 \%$ among 13-19-year-olds and generally declining with age.

The percentage of married people who reported at least one casual partner in the past year ranged from 3\% to $6 \%$. Condom use at last sex with their casual partner underwent a change in trend over time. Condom use with a casual partner among married people was $67 \%$ in $1997,56 \%$ in $1999,50 \%$ in $2000,57 \%$ in 2001, 55\% in 2003 and $59 \%$ in 2005 (p change in trend $=0.015)$. The numbers were small so that the changing trend was not statistically significant for either sex, although both sexes showed the same trend. Among married men the percentage who used a condom at last sex with a casual partner was $71 \%$ in $1997,61 \%$ in $1999,59 \%$ in $2000,62 \%$ in $2001,61 \%$ in 2003 and $63 \%$ in 2005. Although married women were much less likely than men to report a casual partner, those who did were also less likely to use a condom with that partner. Corresponding figures of condom use at last sex with a casual partner among married women were $40 \%$ in $1997,22 \%$ in 1999 , $8 \%$ in $2000,25 \%$ in $2001,24 \%$ in 2003 and 38\% in 2005.

In some cases, trends in condom use were the opposite of trends in casual partners. For example, among those aged 35+ years, casual partners rose between 2000 and 2005, indicating more risky behaviour, but condom use also rose, indicating less risky behaviour. In order to assess the overall trend in "risky behaviour", we therefore combined both condom use and casual partners (fig 5). For most age groups risky behaviour-as measured by casual partners and condom use-appears to have risen between 1997 and 2001 and then declined.
Figure 4 Use of condom at last sex by age of respondent and partnership type.

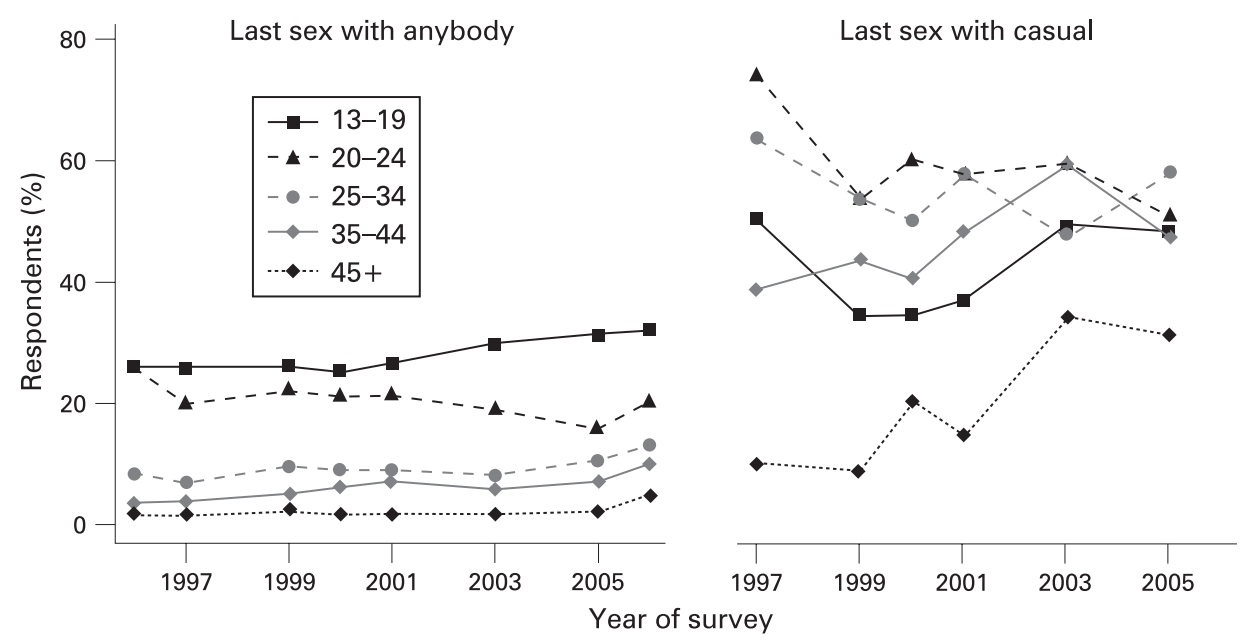


Figure 5 Risk taking behaviour by survey year and age (combining casual partners and condom use).

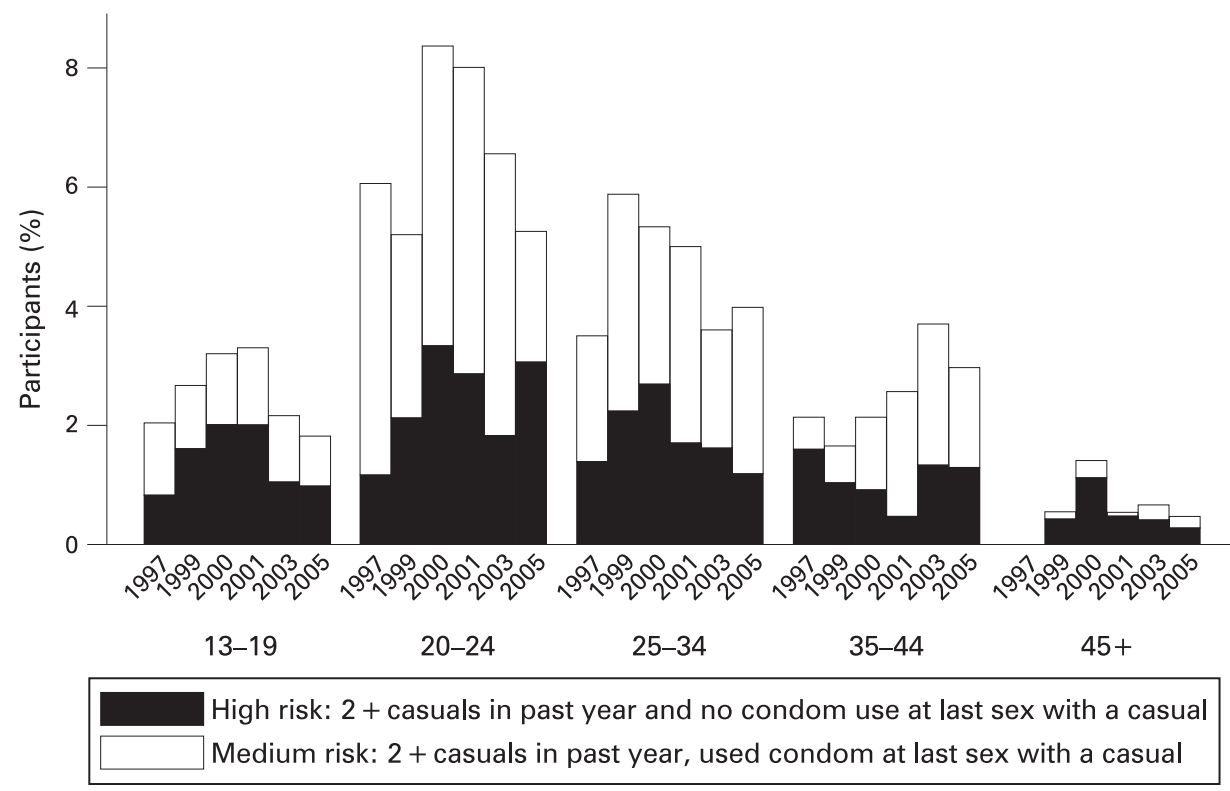

\section{DISCUSSION}

This study describes the trends in sexual behaviour from a rural Ugandan cohort during the period 1993-2006. The evolving pattern was not consistent across the different variables investigated and across different subgroups of the population. A summary of the indicators and trends described in this paper is shown in table 2. On the positive side, there was a clear increase in reported median age at first sex for both young men and women and, in line with this, the percentage of young men and women who reported primary abstinence increased. Overall, reported secondary abstinence also increased, albeit more clearly so in young men. Levels of reported condom use at the last sexual act have increased over time and are quite high, particularly among those not currently married reaching, for example, nearly $50 \%$ among men aged $20-24$ years.

On the other hand, the percentage of young women aged 1319 years who experienced pregnancies before marriage was rather high at around $7 \%$ and showed little change over time. The percentage of never married women aged $21-29$ years who became pregnant increased from $53 \%$ to nearly $70 \%$ and started to fall somewhat only by 2004. Both observations suggest that sexual risk taking among young women may have increased during the observation time. With respect to casual partners, although total numbers were low, the percentage of women reporting sexual intercourse with one or more such partners during the last 12 months tripled between 1997 and 2004, a trend that has only slowly reversed thereafter. Casual sex was much more often reported by men. The trend among men was similar to that reported by women over time, although the increase until 2004 was much weaker. Perhaps most important is the observation that condom use with casual partners showed a declining trend over time for these age bands and by 2005 no longer exceeded 60\%, as had been the case by 1997. Interestingly, condom use with casual partners rose steeply over time in those aged $35-44$ years and $\geqslant 45$ years, with men contributing most of the data. All in all, the evolving picture is a mixed one.

Several of our observations mirror developments in other parts of Uganda and in some other African countries. The encouraging increase in the age of sexual debut continues the trend reported during the early 1990s in Uganda. ${ }^{36}$ This increase has also been observed in Zimbabwe, Kenya and Ghana. ${ }^{517}$ An increase in secondary abstinence has been noted among women from 18 AIDS-affected African countries during the 1990s, during which time the median percentage of women reporting no sexual activity during the past 3 months rose from $44 \%$ to $49 \%$, and rose significantly in 7 out of 18 countries. ${ }^{18}$ Condom use has reached high levels among young sexually active people elsewhere in Uganda. In a study of school-going youth in western Uganda, ever use of condoms was reported to have increased from 50\% in 1996 to $73 \%$ in $2001,{ }^{19}$ and $80 \%$ of schoolgoing young men and $72 \%$ of young women in urban areas reported condom use at the last sexual act in $2003 .^{20}$ Again, this reinforces a development that had already begun in Uganda before $1997 .^{21}$

The worrying levels of sexual relationships with casual partners and observations about insufficient condom use with such partners have also been observed elsewhere in Uganda and Africa. In a recent study, $51 \%$ of men and $32 \%$ of women among the work force of a sugar factory in southern Uganda reported multiple sex partners in the past year, and only $36 \%$ of the respondents reported condom use for the last sex act with a casual partner. ${ }^{22}$ High levels of unprotected sex with multiple partners have been reported recently in other countries in southern Africa such as Botswana. ${ }^{23}$

Not all countries have observed similar trends to Uganda. For example, in a cohort from Tanzania followed from 1995 to 2000, most individuals felt that they were not at risk from HIV infection and sexual risk behaviour remained largely unchanged. ${ }^{24}$

The question arises whether the trends in reported sexual behaviour may help to explain recent changes in the trend of the HIV epidemic. Our sexual behaviour data are from the same population in which we documented that, since about the year 2000, the prevalence and incidence of HIV were no longer falling. ${ }^{25}$ The data reported in the paper presented here do not link reported sexual risk factors and incident HIV infection. However, we noted that a number of temporary or maintained decreases in protective behaviour occurred during the period from 1998 to 2002. For example, while primary abstinence 
Table 2 Summary of direction and magnitude in trends of sexual behaviour

\begin{tabular}{|c|c|c|c|}
\hline Indicator & Direction of trend & Magnitude & Note \\
\hline \multicolumn{2}{|l|}{ Age at sexual debut } & Girls: $16.7->18.2$ & \multirow[t]{2}{*}{ Small dip in 1998-2001, same trend for boys and girls } \\
\hline Years 1997-2006 & Increasing & Boys: $18.5->19.9$ & \\
\hline \multicolumn{3}{|l|}{ Primary abstinence } & \multirow[t]{2}{*}{ Dip in 1999-2002 for girls, dip in 1998-2000 for boys } \\
\hline Years 1993-2006 & Increasing & $72->83 \%$ & \\
\hline \multicolumn{4}{|l|}{ Secondary abstinence } \\
\hline \multicolumn{4}{|l|}{ Years 1997-2006 } \\
\hline Age 13-19 & Increasing & Girls: $12->14 \%$ & \multirow[t]{2}{*}{ Same trend for boys and girls } \\
\hline All other ages & No change & Boys: $10->21 \%$ & \\
\hline \multicolumn{4}{|l|}{ Pregnancy } \\
\hline \multicolumn{4}{|l|}{ Years 1996-2003 } \\
\hline Age 13-20 & Increasing & $8->10 \%$ & \multirow[t]{5}{*}{ Pregnancy among never married young women } \\
\hline Age 21-29 & Increasing & $53->81 \%$ & \\
\hline \multicolumn{3}{|l|}{ Years 2003-2005 } & \\
\hline Age 13-20 & Decreasing & $10->6 \%$ & \\
\hline Age $21-29$ & Decreasing & $81->66 \%$ & \\
\hline \multicolumn{4}{|l|}{ Age at first marriage } \\
\hline \multicolumn{4}{|l|}{ Years 1998-2006 } \\
\hline Age 13-29 (women) & Increasing & $19.0->19.4$ & \\
\hline Age 13-29 (men) & Increasing & $24.9->25.3$ & \\
\hline \multicolumn{4}{|c|}{ Time (years) from sexual debut to first marriage } \\
\hline \multicolumn{4}{|l|}{ Years 1998-2006 } \\
\hline Age 13-29 (women) & No change & $\sim 2.2$ throughout & \\
\hline Age 13-29 (men) & Decreasing & $7.9->6.9$ years & \\
\hline \multicolumn{4}{|c|}{$\geqslant 1$ casual partners in past year } \\
\hline Years 1997-2001 & Increasing & Men: $11.6->12.6 \%$ & \multirow{4}{*}{$\begin{array}{l}\text { Same trend for all groups except men aged } 20-24 \text { years and } \\
25-34 \text { years who showed a continuous rise in casual } \\
\text { partners throughout the entire period (1997-2006) }\end{array}$} \\
\hline & & Women: $1.4->3.6 \%$ & \\
\hline \multirow[t]{2}{*}{ Years 2001-2006 } & Decreasing & Men: $12.6->10.2 \%$ & \\
\hline & & Women: $3.6->1.4 \%$ & \\
\hline \multirow{2}{*}{\multicolumn{2}{|c|}{$\begin{array}{l}\geqslant 2 \text { casual partners in past year } \\
\quad \text { Years } 1997-2006\end{array}$}} & & \multirow{2}{*}{$\begin{array}{l}\text { Similar trend as for } \geqslant 1 \text { casual partners except that the } 35- \\
44 \text { age group showed a continuous increase throughout }\end{array}$} \\
\hline & & & \\
\hline \multicolumn{4}{|c|}{ Condom use ever } \\
\hline \multirow[t]{2}{*}{ Years 1993-2006 } & Increasing & Men: $12.5->46.1 \%$ & \multirow[t]{2}{*}{ Same trend for men and women, all ages } \\
\hline & & Women: $4.0->30.7 \%$ & \\
\hline Condom use at last sex wi & & & \\
\hline Years 1996-2003 & & & \\
\hline Men & Decreasing & $18.9->14.7 \%$ & Women: Although a generally rising trend throughout, \\
\hline Women & Increasing & $5.7->8.0 \%$ & women experienced a dip in condom use between 2001 and \\
\hline Years 2003-2006 & & & s \\
\hline Men & Increasing & $14.7->18.1 \%$ & \\
\hline Women & Increasing & $8.0->9.9 \%$ & \\
\hline Condom use at last sex wi & & & \\
\hline Years 1997-2005 & & & \\
\hline Age $20-24$ & Decreasing & $74.1->50.7 \%$ & Among those age $13-19$ years, condom use with a casual \\
\hline Age $25-34$ & Decreasing & $63.8->58.2 \%$ & decreased from 1997 to 2000 , then increased from 2000 to \\
\hline Age $35-44$ & Increasing & $38.9->47.6 \%$ & 2005 \\
\hline Age $45+$ & Increasing & $10.0->31.3 \%$ & \\
\hline Age $13-19$ & Decrease->Increase & $50.6->48.2 \%$ & \\
\hline
\end{tabular}

among youth aged 13-19 years generally increased over time, there was a short period between 1998 and 2002 during which it dipped. Changes in other indicators also seem to be consistent with the increase in transmission risk during that period, such as increases in reported pregnancy among unmarried young women, temporary declines in age at sexual debut and temporary declines in reported secondary sexual abstinence and condom use with casual partners (eg, in the youngest age group). The proportion of both men and women who reported a casual partner in the past year rose steadily from 1997 to 2001. In the period between 1996 and 2002 there was an increase in the proportion of married men in the 25-34 years and 3544 years age groups reporting $\geqslant 2$ partners in the past year. The proportion who reported casual partners in these two age groups continued to rise until 2004, when the incidence was rising as a whole, and a second peak of incidence was also observed among women in their 30s and men in their 40s. ${ }^{25}$ However, while these observations are sufficiently strong to inform public health and policy and call for a renewed emphasis on prevention efforts in Uganda, definite conclusions regarding a link between observed sexual behaviour and epidemiological trends are not yet possible.

In addition to previously identified public health messages, the results of our study point to the need for a mix of groupspecific prevention efforts. For example, our data show that risky behaviour may be increasing among older people, and this has coincided with an increase in the prevalence and incidence of HIV in this group. At the same time, condom use (even with 
casual partners) consistently declined with increasing age, creating a prevention gap that needs to be addressed.

At the advanced stage of the epidemic in which Uganda and most sub-Saharan African countries now fall, most HIV transmissions occur within stable partnerships. ${ }^{26}{ }^{27}$ For a variety of reasons, condom use within marriages is very low, even among HIV-discordant couples. ${ }^{28-30}$ In many parts of Africa married couples find it difficult to accept condom use. ${ }^{30}$ For example, while the national survey of 2004 in Uganda showed that protected sex within marriages occurred three times more often among infected partners who knew their status than among those who did not, condom use was still low. ${ }^{1}$ In addition to the traditional focus on avoiding extramarital sexual contacts, prevention programmes in mature epidemics should pay greater attention to HIV protection within stable partnerships. Barriers to couple testing ${ }^{31} 32$ in Africa have been well documented. Raising awareness of the issue of serodiscordance might remove one of the most important barriers to HIV testing $^{33}$ by challenging the notion that mutual infection is inevitable once one couple member becomes infected. It is, however, likely that, in spite of all efforts, condom use in marriage will remain low even among discordant couples who know their HIV status. Alternative intervention strategies are needed. If shown to be effective, these may include microbicides, post-exposure prophylaxis, early initiation of antiretroviral therapy (ART), suppression of herpes simplex virus-2 infection and, ultimately, a vaccine against HIV infection.

\section{Limitations and possible biases}

Our study includes some possible biases. Just 57\% of the population who participated in the census provided information on sexual behaviour in any given round. Individuals who did not respond may have higher risk taking behaviour. However, the bias is unlikely to have changed over time, so observed trends should not be affected. Also, some questions were not always asked the same way and this may have introduced bias. For example "ever had sex" was a direct question in 1993 but, from 1997, it was derived from the reported age at first sex.

Another possible bias regards data quality. Interviews were administered face-to-face. During the consent process the respondents were reassured of confidentiality of the interviews; however, some social desirability bias may exist. In addition, we used open-ended classification while obtaining responses on number of partners and may therefore have failed to identify those very few individuals who have very large numbers of partners. Men report much higher numbers of casual partners and also higher condom use than women. Yet, in this comparatively closed society, these findings are questionable. With regard to partnership type, the difference in reporting could be a question of perception of partnership type as women and men may have different perceptions about the seriousness of partnerships. ${ }^{34}$ It is most likely that men over-report while women under-report, a phenomenon observed in most sexual behaviour surveys. ${ }^{35}$ An interpretation that would make the reporting trends between men and women consistent is that there may be some women who have many sexual partners while most have just one regular partner. The data do not justify this interpretation, however, as $1.12 \%$ of men over time have claimed $\geqslant 5$ casual partners in the past year and $1.68 \%$ have claimed $\geqslant 5$ partners of any type, while only $0.02 \%$ of women have claimed $\geqslant 5$ casual partners and $0.06 \%$ have claimed $\geqslant 5$ partners of any type.

It is unclear why some people in this population began engaging in more risky sexual behaviour. Some researchers have

\section{Take-home messages}

- The changes in sexual behaviour in this cohort were not consistent across the variables and subgroups investigated.

- Some indicators showed encouraging trends toward safer sexual behaviour, particularly among young people.

- Other indicators suggest an increase in sexual risk taking, particularly among middle-aged and older adults.

- These changes may help explain recent changes in epidemiological trends in Uganda, but more work is required to establish such links if they exist.

suggested that "normalisation" may have contributed to this, with HIV now becoming a normal part of life, possibly leading to complacency. ${ }^{36}$ We believe it unlikely that the introduction of ART influenced trends in sexual behaviour in this study. If anything, after a period of increased risky behaviour, risky sexual behaviour appears to be declining in 2004/5, at the time that ART was introduced. Also, by 2006 , only about $20 \%$ of the HIV-positive respondents were receiving ART. So far, several studies from Uganda seem to indicate that the availability of ART has not introduced disinhibition of sexual behaviour, either among ART recipients or in the general population. ${ }^{37}$

\section{CONCLUSION}

In this rural cohort we observed a number of changes in sexual behaviour between 1993 and 2006. The main findings were:

- The changes in sexual behaviour were not consistent across the variables and subgroups investigated.

- Some indicators showed encouraging trends towards safer sexual behaviour, particularly among young people.

- Other indicators suggest an increase in sexual risk taking, particularly among middle-aged and older adults.

- These changes may help explain recent changes in epidemiological trends in Uganda, but more work is required to establish such links if they exist.

While the reasons for the observed behaviour changes are not well understood, our observations suggest that HIV prevention messages should be reinforced and should be adapted to the needs of particular subgroups. Even though we are more than 20 years into the epidemic, and even though Uganda was a leader in promoting public health awareness and prevention of HIV throughout the 1990s, we must not relax.

Acknowledgements: The authors thank Jim Todd and Lieve van der Paal for comments on the manuscript and Joseph Ouma and Duncan Ssematimba for data management.

Funding: Funded by the UK Medical Research Council.

Competing interests: None.

Ethics approval: The study was approved by the Science and Ethics Committee of the Uganda Virus Research Institute and the Uganda National Council of Science and Technology.

Contributors: SB and LAS conducted literature review and wrote the manuscript. LAS and IK conducted statistical analyses. BW, a social scientist, advised on aspects of the paper such as which combination of sexual behaviour indicators to analyse. AK and AN are the team leaders, overseeing data collection and field activity within the cohort described in this paper; they both contributed with a deep understanding of the community norms and values. JM, WK and AO provided useful input from the side of the Ugandan $\mathrm{MoH}$, such as trends in $\mathrm{MoH}$ antenatal clinics and trends in sexual behaviour found in the $\mathrm{MoH}$ serobehavioural survey. JW was the director of the Medical Research Council Programme on AIDS (Uganda) from 1995 to 2001 and HG has been the director since 2002. All co-authors contributed to decisions on the content of the paper and all co-authors commented on drafts of the paper. 


\section{REFERENCES}

1. Bunnell R, Opio A, Musinguzi J, et al. HIV transmission risk behaviour among HIVinfected adults in Uganda: results of a nationally representative survey. AIDS 2008;22:617-24.

2. Kirungi WL, Musinguzi J, Madraa E, et al. Trends in antenatal HIV prevalence in urban Uganda associated with uptake of preventive sexual behaviour. Sex Transm Infect 2006;82(Suppl 1):i36-41.

3. Kamali A, Carpenter LM, Whitworth JAG, et al. Seven-year trends in HIV-1 infection rates, and changes in sexual behaviour among adults in rural Uganda. AIDS 2000;14:427.

4. Pool R, Kamali A, Whitworth J. Understanding sexual behaviour change in rural southwest Uganda: a multi-method study. AIDS Care 2006;18:479-88.

5. Żaba B, Pisani E, Slaymaker E, et al. Age at first sex: understanding recent trends in African demographic surveys. Sex Transm Infect 2004;80:ii28-35.

6. Asiimwe-0kiror G, Opio A, Musinguzi J, et al. Changes in sexual behaviour and decline in HIV infection among young pregnant women in urban Uganda. AIDS 1997;11:1757-63.

7. Kamya M, McFarland W, Hudes E, et al. Condom use with casual partners by men in Kampala, Uganda. AIDS 1997;11:S61-6.

8. Stoneburner L, Low-Beer D. Population-level HIV declines and behavioural risk avoidance in Uganda. Science 2004;304:714-7.

9. Hallett TB, Aberle-Grasse J, Bello G, et al. Declines in HIV prevalence can be associated with changing sexual behaviour in Uganda, urban Kenya, Zimbabwe, and urban Haiti. Sex Transm Infect 2006;82:11-8.

10. Mbulaiteye S, Mahe C, Whitworth J, et al. Declining HIV-1 incidence and associated prevalence over 10 years in a rural population in south-west Uganda: a cohort study. Lancet 2002;360:41-6.

11. Mulder D, Nunn A, Kamali A, et al. Decreasing HIV-1 seroprevalence in young adults in a rural Ugandan cohort. BMJ 1995:311:833-6.

12. UNAIDS/WHO Working Group on Global HIV/AIDS and STI Surveillance Guidelines for second generation HIV surveillance. Geneva: World Health Organization and Joint United Nations Programme on HIV/AIDS, 2000.

13. Mulder D, Nunn A, Kamali A, et al. Two-year HIV-1-associated mortality in a Ugandan rural population. Lancet 1994:343:1021-3.

14. Mulder D, Nunn A, Wagner H, et al. HIV-1 incidence and HIV-1-associated mortality in a rural Ugandan population cohort. AIDS 1994;8:87-92

15. Wolff B, Nyanzi B, Katongole G, et al. Evaluation of a home-based voluntary counselling and testing intervention in rural Uganda. Health Policy Plann 2005:20:109-16.

16. Wringe A, Cremin I, Todd J, et al. Comparative assessment of the quality of age-atevent reporting in three HIV cohort studies in sub-Saharan Africa. Sex Transm Infect 2009;85(Suppl I):i56-i63.

17. Gregson S, Garnett G, Nyamukapa C, et al. HIV decline associated with behaviour change in eastern Zimbabwe. Science 2006;311:664-6.

18. Cleland J, Ali M. Sexual abstinence, contraception, and condom use by young African women: a secondary analysis of survey data. Lancet 2006;368:1749-50.

19. Kilian A, Kipp W, Jhamgri G, et al. Trends in HIV infection: prevention-related attitudes and behaviour among secondary school students in western Uganda. J Acquir Immune Defic Syndr 2007;44:586-93.
20. Twa-Twa J, Oketcho S, Siziya S, et al. Prevalence and correlates of condom use at last sexual intercourse among in-school adolescents in urban areas of Uganda. East Afr J Public Health 2008;5:22-5.

21. Konde-Lule J, Tumwesigye M, Lubanga R. Trends in attitudes and behaviours relevant to AIDS in the Ugandan community. East Afr Med J 1997;74:406-10.

22. Buregveya $\mathbf{E}$, Bazeyo W, Moen B, et al. HIV risk behaviour and work in Uganda: a cross-sectional study. East Afr J Public Health 2008;5:43-8.

23. Kalichman S, Ntseane D, Nthomang K, et al. Recent multiple sexual partners and HIV transmission risks among people living with HIV/AIDS in Botswana. Sex Transm Infect 2007:83:371-5.

24. Mwaluko G, Urassa M, Isingo R, et al. Trends in HIV and sexual behaviour in a longitudinal study in a rural population in Tanzania, 1994-2000. AIDS 2003;17:2645-51.

25. Shafer L, Biraro S, Nakiyingi-Miiro J, et al. HIV Prevalence and incidence are no longer falling in Southwest Uganda: evidence from a rural population cohort 19892005. AIDS 2008;22:1641-9.

26. Grosskurth H, Gray R, Hayes R, et al. Control of sexually transmitted diseases for HIV-1 prevention: understanding the implications of the Mwanza and Rakai trials. Lancet 2000;355:1981-7.

27. Glynn J, Carael M, Buve A, et al. HIV risk in relation to marriage in areas with high prevalence of HIV infection. J AIDS 2003;33:526-35.

28. Akurut D, Wolff B, Kasamba I, et al. Should we use them without end? Negotiation of condom starting and stopping in new sexual relationships in rural Uganda. Seminar on Potential and Actual Contributions of Behavioural Change to Curbing the Spread of HIV. Entebbe, Uganda, 18-20 Feb 2008.

29. Bunnell R, Opio A, Musinguzi J, et al. HIV transmission risk behavior among HIVinfected adults in Uganda: results of a nationally representative survey. AIDS 2008;22:617-24.

30. Chimbiri AM. The condom is an 'intruder' in marriage: evidence from rural Malawi. Soc Sci Med 2007:64:1102-15.

31. Glick P. Scaling Up HIV Voluntary counseling and testing in Africa: what can evaluation studies tell us about potential prevention impacts? Eval Rev 2005;29:331.

32. Maman S, Mbwambo J, Hogan NM, et al. Women's barriers to HIV-1 testing and disclosure: challenges for HIV-1 voluntary counselling and testing. AIDS Care 2001;13:595-603.

33. Bunnell RE, Nassozi J, Marum E, et al. Living with discordance: knowledge, challenges, and prevention strategies of HIV-discordant couples in Uganda. AIDS Care 2005;17:999-1012.

34. Nnko S, Boerma J, Urassa M, et al. Secretive females or swaggering males? An assessment of the quality of sexual partnership reporting in rural Tanzania. Soc Sci Med 2004;59:299-310.

35. Munguti K, Grosskurth $\mathrm{H}$, Newell J, et al. Patterns of sexual behaviour in a rural population in north-western Tanzania. Soc Sci Med 1997:44:1553-61.

36. Uganda AIDS Commission. Accelerating HIV prevention in Uganda: the road towards universal access. Uganda: Ministry of Health, 2006.

37. Kaida A, Gray G, Bastos F, et al. The relationship between HAART use and sexual activity among HIV-positive women of reproductive age in Brazil, South Africa and Uganda. AIDS Care 2008;20:21-5. 